\title{
OWA operators in the calculation of the average green-house gases emissions
}

\author{
Keivan Amirbagheri ${ }^{\mathrm{a}, \mathrm{d}^{*}}$, José M. Merigó ${ }^{\mathrm{b}, \mathrm{c}}$, Laura Guitart-Tarrés ${ }^{\mathrm{d}}$, Ana Nuñez-Carballosa ${ }^{\mathrm{d}}$ \\ ${ }^{a}$ Department of Industrial Organization - Academic Area, Escola Universitària Salesiana de Sarrià, Paseo Sant Joan \\ Bosco, 74, 08017 Barcelona, Spain \\ ${ }^{b}$ Department of Management Control and Information Systems, School of Economics and Business, University of \\ Chile, Av. Diagonal Paraguay 257, 8330015 Santiago, Chile \\ ${ }^{c}$ School of Systems, Management and Leadership, Faculty of Engineering and Information Technology, University of \\ Technology Sydney, 81 Broadway, Ultimo 2007, NSW, Australia \\ ${ }^{d}$ Department of Economics and Business, Faculty of Economics and Business, University of Barcelona, Av. Diagonal \\ 690, 08034 Barcelona, Spain \\ * Corresponding author: kamirbam7@alumnes.ub.edu
}

\begin{abstract}
This study proposes, through weighted averages and ordered weighted averaging operators, a new aggregation system for the investigation of average gases emissions. We present the ordered weighted averaging operators gases emissions, the induced ordered weighted averaging operators gases emissions, the weighted ordered weighted averaging operators gases emissions and the induced probabilistic weighted ordered weighted averaging operators gases emissions. These operators represent a new way of analyzing the average gases emissions of different variables like countries or regions. The work presents further generalizations by using generalized and quasiarithmetic means. The article also presents an illustrative example with respect to the calculations of the average gases emissions in the European region.
\end{abstract}

Keywords: Green-house gases emission, aggregation operators, decision making, ordered weighted average.

\section{Introduction}

Within the exceptionally later decades, since of an gigantic development of the population and the need to supply nourishment for them from one hand and the other hand an immethodical utilization of fossil fuel, our planet is experiencing an unexampled growth in terms of green-house gases (GHG) emission such as $\mathrm{CO}_{2}, \mathrm{CH}_{4}$ and $\mathrm{N}_{2} \mathrm{O}$ in its atmosphere that cause an ascending amount of global warming year by year and a drastic climate change [13,15,37].

There are many works that study the ways that can lead the GHG emission toward the minimization. [36], evaluate the potential influence of vehicle electrification on grid infrastructure and road-traffic green-house emission. [12] Study the impact of electrical power generation on GHG emission in Europe, [10] analyze green-house gases emission in concrete manufacture while there are some papers that focus on agriculture and farming $[4,17,35]$.

Besides, although these works exist but it seems vital to present a comprehensive forecast about the future of countries based on the experts' opinions to provide a clear plan and make a suitable decision to decrease this emission in any of the studied sectors and under various conditions.

Aggregation operators in the related literature with the aim of decision making are diverse and each of them can be used to collect the information [3,26-29]. These techniques give importance to the variables according to certain available subjective or objective findings [34,31,38,40,42].

A very popular aggregation operator is the weighted average. This aggregation operator is flexible to use in a wide range of problems. Another popular aggregation operator is the ordered weighted average (OWA) [41,45]. The OWA operator provides a parametrized family of aggregation operators between the minimum and the maximum, weighting the data according to the attitudinal character of the decisionmaker. Based on this operator and with the purpose of expanding it, many authors expand and generalize it $[9,16,24,39,46]$. There are several types for the concept of expanding and generalizing and the most important item is the form of integrating OWA operator with some key concepts such as, using the induced variables, the probability and the weighted average. [40] propose some new aggregation operators such as the induced ordered weighted geometric averaging (IOWGA) operator, generalized 
induced ordered weighted averaging (GIOWA) operator, hybrid weighted averaging (HWA) operator.

The purpose of this work is to concentrate on the analysis of the use of the aggregation operators in the calculation of green-house gases (GHG) emission with the aim of developing better decision-making techniques. To this end, the paper studies several aggregation operators including the WA [3], OWA [23,41], OWAWA and IOWAWA [25], IOWA [44], POWAWA and IPOWAWA operator [29]. With the use of each operator, a new operator for GHG emission is produced including the OWA GHG emission (OWAGE), induced OWA GHG emission (IOWAGE), ordered weighted averaging weighted average GHG emission (OWAWAGE), induced OWAWA GHG emission (IOWAWAGE), probabilistic OWAWA GHG emission (POWAWAGE) and induced probabilistic OWAWA GHG emission (IPOWAWAGE).

The work also presents further generalizations by using generalized and quasi-arithmetic means obtaining the generalized OWAGE (GOWAGE). The aim of this approach is to show a more general framework in the analysis of averages by using complex aggregations including with geometric and quadratic averages. The study presents a wide range of particular types of aggregations under this approach.

During the related literature there are several works dedicated to the application of these aggregation operators such as, demand analysis [32], economic growth analysis [33], portfolio selection [18], support vector machines [22] and the average price [30]. On the other hand, many works are dedicated to making decision in different fields to solve the problem. As an example, [7] with mixing induced OWA operators and Minkowski distances, try to present a method to decide in reinsurance. [8] present a new method for handling multi-criteria fuzzy decision-making problems by using FN-IOWA operators or in the other study, [14] analyse the origin and uses of the ordered weighted geometric operator in multicriteria decision making and [21], proposes a model for the best-suited OWA operators and [6] by using bibliometric method review the contribution in fuzzy decision-making area. This work develops OWA operators in the analysis of the average green-house gases emissions.

The work presents an application regarding the calculation of the average gases emissions in Europe. For doing so, the paper considers a multi-expert aggregation problem where four experts analyze the expected average emissions of each European country for the next period. From, the analysis develops several aggregation methods based on the tools developed in the paper including the OWAGE, IOWG and OWAWAGE operators. The main advantage of the OWA operator is the possibility of under or overestimate the information according to the attitudinal character of the decision maker. Thus, depending on the degree of optimism or pessimism of the decision maker, the results may lead to different decisions and interpretations of the information.

This paper is organized as follows. Section 2 briefly reviews some basic OWA operators. Section 3 introduces the use of the OWA operator in the calculation of the average green-house gases emissions. Section 4 develops further generalization with generalized and quasi-arithmetic means. Section 5 presents an illustrative example regarding the calculation of average gases emissions with OWA operators. Section 6 ends the paper summarizing the main findings and conclusions of the paper.

\section{Preliminaries}

\subsection{The induced OWA operator (IOWA)}

The IOWA operator [44] is an extension of the OWA operator. The main difference between OWA and IOWA is that the reordering step is not developed with the values of the arguments $a_{i}$. In this case, the reordering step is carried out with order inducing variables. The IOWA operator also includes as particular cases the maximum, the minimum and the average criteria. It can be defined as follows.

Definition 1. An IOWA operator of dimension $n$ is a mapping IOWA: $R^{n} \times R^{n} \rightarrow R$ that has an associated weighting vector $\mathrm{W}$ of dimension $n$ with $\sum_{j=1}^{n} w_{j}=1$ and $w_{j} \in[0,1]$, such that:

$$
\operatorname{IOWA}\left(\left\langle u_{1}, a_{1}\right\rangle,\left\langle u_{2}, a_{2}\right\rangle, \ldots,\left\langle u_{n}, a_{n}\right\rangle\right)=\sum_{j=1}^{n} w_{j} b_{j},
$$

where $b_{j}$ is the $a_{i}$ value of the IOWA pair $\left\langle u_{i}, a_{i}\right\rangle$ having the $j$ th largest $u_{i} . u_{i}$ is the order-ranking variable and $a_{i}$ is the argument variable.

\subsection{The ordered weighted averaging-weighted average (OWAWA)}

The OWAWA operator [25] is a new model that unifies the OWA operator and the weighted average in the same formula. Therefore, both concepts can be seen as a particular case of a more general one. It can be defined as follows.

Definition 2. An OWAWA operator of dimension $n$ is a mapping $O W A W A: R^{n} \rightarrow R$ that has an associated weighting vector $\mathrm{W}$ of dimension $n$ such that 
$w_{j} \in[0,1]$ and $\sum_{j=1}^{n} w_{j}=1$, according to the

following formula:

$\operatorname{OWAWA}\left(a_{1}, \ldots, a_{n}\right)=\sum_{j=1}^{n} \hat{v}_{j} b_{j}$

where $b_{j}$ is the $j$ th largest of the $a_{i}$, each argument $a_{i}$ has an associated weight (WA) $v_{i}$ with $\sum_{i=1}^{n} v_{i}=1$ and $v_{i} \in[0,1], \hat{v}_{j}=\beta w_{j}+(1-\beta) v_{j}$ with $\beta \in[0,1]$ and $v_{j}$ is the weight (WA) $v_{i}$ ordered according to $b_{j}$, that is, according to the $j$ th largest of the $a_{i}$.

\subsection{The probabilistic ordered weighted averaging-} weighted average (POWAWA)

The POWAWA [34] operator uses probabilities, weighted average and OWA in the same formulation. It unifies these three concepts by considering the degree of importance that each concept has in the aggregation, depending on the situation considered. The POWAWA operator is defined as follows.

Definition 3. A POWAWA operator of dimension $n$ is a mapping POWAWA: $R^{n} \rightarrow R$ that has an associated weighting vector $W$ of dimension $n$ with $w_{j} \in[0,1]$ and $\sum_{j=1}^{n} w_{j}=1$ such that:

$\operatorname{POWAWA}\left(a_{1}, a_{2}, \ldots, a_{n}\right)=\sum_{j=1}^{n} \hat{v}_{j} b_{j}$

where $b_{j}$ is the $j$ th largest of the $a_{i}$, each argument $a_{i}$ has an associated weight $v_{i}$ with $\sum_{i=1}^{n} v_{i}=1$ and $v_{i} \in[0,1]$, a probability $p_{i}$ with $\sum_{i=1}^{n} p_{i}=1$ and $p_{i} \in[0,1], \quad \hat{v}_{j}=C_{1} w_{j}+C_{2} v_{j}+C_{3} p_{j}$, with $C_{1}, C_{2}$ and $C_{3} \in[0,1], C_{1}+C_{2}+C_{3}=1$ and $v_{j} p_{j}$ are the weights $v_{i}$ and $p_{i}$ ordered according to $b_{j}$, that is to say, according to the jth largest of the $a_{i}$.

\subsection{The induced probabilistic OWAWA operator}

The IPOWAWA [29] is an aggregation operator that extends POWAWA operator that uses order-inducing variables that represent complex reordering processes of an aggregation. Thus, it is an aggregation operator that uses induced variables, the probability, the weighted average and the OWA operator. Moreover, it can assess complex reordering processes by using order-inducing variables. Its main advantage is that it provides a more robust formulation than the
POWAWA operator because it includes a wide range of cases. It can be defined as follows.

Definition 4. The IPOWAWA operator of dimension $n$ is a mapping IPOWAWA: $R^{n} \times R^{n} \rightarrow R$ that has an associated weighting vector $W$ of dimension $n$ with $w_{j} \in[0,1]$ and $\sum_{j=1}^{n} w_{j}=1$, such that:

IPOWAWA $\left(\left\langle u_{1}, e_{1}\right\rangle,\left\langle u_{2}, e_{2}\right\rangle, \ldots,\left\langle u_{n}, e_{n}\right\rangle\right)=\sum_{j=1}^{n} \hat{v}_{j} b_{j}$

where $b_{j}$ is the $a_{i}$ value of the IPOWAWA pair $\left\langle u_{i}, e_{i}\right\rangle$ having the $j$ th largest $u_{i}, u_{i}$ is the orderinducing variable, each argument $a_{i}$ has an associated weight $v_{i}$ with $\sum_{i=1}^{n} v_{i}=1$ and $v_{i} \in[0,1]$, a probability $p_{i}$ with $\quad \sum_{i=1}^{n} p_{i}$ and $p_{i} \in[0,1], \quad \hat{v}_{j}=C_{1} w_{j}+C_{2} v_{j}+C_{3} p_{j}$, with $C_{1}, C_{2}$ and $C_{3} \in[0,1], C_{1}+C_{2}+C_{3}=1, v_{j}$ and $p_{j}$ are the weights $v_{i}$ and $p_{i}$ ordered according to $b_{j}$, that is to say according to the $j$ th largest of the $e_{i}$.

\section{Calculation of the average green-house gases (GHG) emission with OWA operators}

The purpose of this paper is to calculate the average GHG emission. The average GHG emission represents a numerical value that reports the information of the GHG emission. To calculate this item, using many aggregation operators is possible likewise normal arithmetic mean. These possible aggregation operators could be WA, OWA, IOWA or a combination of them such as OWAWA, IOWAWA, etc. Through using them we prepare some possibilities for the future of GHG emission in different scenarios in a spectrum from the worst case to the best case based on experts' opinions.

The basic operator for analyzing a set of GHG emission is OWAGE. The OWAGE operator is an aggregation operator that analyses an average GHG emission under uncertainty situation. It can be defined as follows for the set of GHG emission $A=\left\{e_{1}, e_{2}, \ldots, e_{n}\right\}$ :

$\operatorname{OWAGE}\left(e_{1}, e_{2}, \ldots, e_{n}\right)=\sum_{j=1}^{n} w_{j} f_{j}$

where $f_{j}$ is the $j$ th largest of the $e_{i}$.

The other significant aggregation operator is the induced OWA (IOWA) that its reordering step is developed with order including variables. So, by using the IOWA operator we obtain IOWA GHG emission (IOWAGE) that can be defined as follows: 
$\operatorname{IOWAGE}\left(\left\langle u_{1}, e_{1}\right\rangle,\left\langle u_{2}, e_{2}\right\rangle, \ldots,\left\langle u_{n}, e_{n}\right\rangle\right)=\sum_{j=1}^{n} w_{j} f_{j}$

where $f_{j}$ is the $e_{i}$ value of the IOWA pair $\left\langle u_{i}, e_{i}\right\rangle$ having the $j$ th largest $u_{i} . u_{i}$ is the order-ranking variable and $e_{i}$ is the argument variable.

It is important to mention that this operator is based on considering no extra information. One of the very important aspects of the average GHG emission is the importance of each of them and in other words, their weights in comparison with each other. To this end it is better to use some approaches of information aggregation that combine OWA operators and WA. In the literature there are some aggregation operators with this structure like, the WOWA operator [38], the hybrid average [26] and the OWAWA operators [25]. In this work we apply OWAWA to obtain the OWAWA GHG emission (OWAWAGE) and it is defined as follows for a set of GHG emission $A=\left\{e_{1}, e_{2}, \ldots, e_{n}\right\}$ :

$\operatorname{OWAWAGE}\left(e_{1}, e_{2}, \ldots, e_{n}\right)=\sum_{j=1}^{n} \hat{v}_{j} f_{j}$

where $f_{j}$ is the $j$ th largest of the $e_{i}$, each argument $e_{i}$ has an associated weight (WA) $v_{i}$ with $\sum_{i=1}^{n} v_{i}=1$ and $v_{i} \in[0,1], \hat{v}_{j}=\beta w_{j}+(1-\beta) v_{j}$ with $\beta \in[0,1]$ and $v_{j}$ is the weight (WA) $v_{i}$ ordered according to $b_{j}$, that is, according to the $j$ th largest of the $e_{i}$.

To focus more deeply on our contributions, we implement IOWAWA which is a combination of IOWA operators and WA in the same formulation. By using the IOWAWA operator we obtain IOWAWA GHG emission (IOWAWAGE) that can be defined as follows:

$\operatorname{IOWAWAGE}\left(\left\langle u_{1}, e_{1}\right\rangle,\left\langle u_{2}, e_{2}\right\rangle, \ldots,\left\langle u_{n}, e_{n}\right\rangle\right)=\sum_{j=1}^{n} \hat{v}_{j} f_{j}$

where $f_{j}$ is the $e_{i}$ value of the IOWAWA pair $\left\langle u_{i}, e_{i}\right\rangle$ having the $j$ th largest $u_{i}, u_{i}$ is the order including variable and $e_{i}$ is the argument variable, each argument $e_{i}$ has an associated weight (WA) $v_{i}$ with $\sum_{i=1}^{n} v_{i}=1$ and $v_{i} \in[0,1], \hat{v}_{j}=\beta w_{j}+(1-\beta) v_{i}$ with $\beta \in[0,1]$ and $v_{j}$ is the weight (WA) $v_{i}$ ordered according to $f_{j}$, that is, according to the jth largest $u_{i}$.

Besides, the other aspect that can be considered and leads results to a better form is probabilities in the attitudinal character of the decision-maker. For this reason, we apply POWAWA operator. By applying the Eq. (3) we could obtain the probabilistic OWAWA GHG emission (POWAWAGE). It can be defined as follows:

POWAWAGE $\left(e_{1}, e_{2}, \ldots, e_{n}\right)=\sum_{j=1}^{n} \hat{v}_{j} f_{j}$

where $f_{j}$ is the $j$ th largest of the $e_{i}$, each argument $e_{i}$ has an associated weight $v_{i}$ with $\sum_{i=1}^{n} v_{i}=1$ and $v_{i} \in[0,1], \quad$ a probability $p_{i}$ with $\quad \sum_{i=1}^{n} p_{i}=1$ and $p_{i} \in[0,1], \quad \hat{v}_{j}=C_{1} w_{j}+C_{2} v_{j}+C_{3} p_{j}, \quad$ with $\quad C_{1}, C_{2}$ and $C_{3} \in[0,1], C_{1}+C_{2}+C_{3}=1$ and $v_{j} \quad p_{j}$ are the weights $v_{i}$ and $p_{i}$ ordered according to $f_{j}$, that is to say, according to the $j$ th largest of the $e_{i}$.

Let us analyze the different families of IOWAWAGE and POWAWAGE in the following paragraphs

First, we are considering the two main cases of the IOWAWAGE operator that are found by analyzing the coefficient $\beta$. Basically:

- If $\beta=0$, we get the WA.

- If $\beta=1$, the IOWA operator.

- If $\beta=1$ and the ordered position of $u_{i}$ is the same than the ordered position of $f_{i}$ such that $f_{j}$ is the $j$ th largest of $e_{i}$, the OWA operator.

- Note that when $\beta$ increases, we are giving more importance to the IOWAGE operator and when $\beta$ decreases, we give more importance to the WA.

Another group of interesting families are the maximum-WAGE, the minimum-WAGE, the stepIOWAWAGE operator and the usual average.

- The maximum-WAGE is found when $w_{p}=1$ and

$$
w_{j}=0 \text {, for all } j \neq p \text {, and } u_{p}=\operatorname{Max}\left\{e_{i}\right\} \text {. }
$$

- The minimum-WAGE is formed when $w_{p}=1$ and

$$
w_{j}=0 \text {, for all } j \neq p \text {, and } u_{p}=\operatorname{Min}\left\{e_{i}\right\} \text {. }
$$

The arithmetic-WAGE is obtained when $w_{j}=1 / n$ for all $j$, and the weighted average is equal to the OWA when the ordered position of $i$ is the same as the ordered position of $j$. The arithmetic-WAGE (AWAGE) can be formulated as follows:

$$
A-W A G E\left(\left\langle u_{1}, e_{1}\right\rangle,\left\langle u_{2}, e_{2}\right\rangle, \ldots,\left\langle u_{n}, e_{n}\right\rangle\right)=\frac{1}{n} \beta a_{i}+(1-\beta) \sum_{i=1}^{n} v_{i} e_{i},
$$

Note that if $v_{i}=1 / n$, for all $i$, then, we get the unification between the arithmetic mean (and simple average) and the IOWAGE operator, that is, the 
arithmetic-IOWAGE (A-IOWAGE). The AIOWAGE operator can be formulated as follows:

$$
\text { A-IOWAGE }\left(\left\langle u_{1}, e_{1}\right\rangle,\left\langle u_{2}, e_{2}\right\rangle, \ldots,\left\langle u_{n}, e_{n}\right\rangle\right)=\beta \sum_{j=1}^{n} w_{j} b_{j}+(1-\beta) \frac{1}{n} e_{i} .
$$

Following the OWA literature $[29,41,43]$, we can develop many other families of IOWAWA operators such as:

- The olympic-IOWAWAGE operator $\left(w_{1}=w_{n}=0\right.$, and $w_{j}=1 /(n-2)$ for all others $)$.

- The general olympic-IOWAWAGE operator $\left(w_{j}=0\right.$ for $j=1,2, \ldots, k, n, n-1, \ldots, n-k+1$; and for all others $w_{j^{*}}=1 /(n-2 k)$, where $\left.k<n / 2\right)$.

- The S-IOWAWAGE (green-house gases emission $)\left(w_{1}=(1 / n)(1-(\alpha+\beta)+\alpha\right.$,

$w_{n}=(1 / n)\left(1-(\alpha+\beta)+\beta\right.$, and $w_{j}=(1 / n)(1-(\alpha+\beta)$ for $j=2$ to $n-1$ where $\alpha, \beta \in[0,1]$ and $\alpha+\beta \leq 1)$.

- The centered-IOWAWAGE (if it is symmetric, strongly decaying from the center to the maximum and the minimum, and inclusive).

Now we consider the different families of POWAWAGE operators that are found in the weighting vector $\hat{V}$ and the coefficients $C_{1}, C_{2}$ and $C_{3}$.

If $\quad w_{1}=1$ and $\quad w_{j}=0$, for all $j \neq 1$, the POWAWAGE operator becomes the maximum probabilistic weighted average GHG emission (MaxPWAGE) which is formulated as follows:

$\operatorname{Max}-P W A G E=C_{1} \operatorname{Max}\left\{b_{j}\right\}+C_{2} \sum_{i=1}^{n} v_{i}\left|x_{i-} y_{i}\right|+C_{3} \sum_{i=1}^{n} p_{i}\left|x_{i-} y_{i}\right|$

If $w_{n}=1$ and $w_{j}=0$, for all $j \neq n$, the POWAWAGE becomes the minimum probabilistic weighted average GHG emission (Min-PWAGE), which is formulated in the following way:

$$
\operatorname{Min}-P W A G E=C_{1} \operatorname{Min}\left\{b_{j}\right\}+C_{2} \sum_{i=1}^{n} v_{i}\left|x_{i-} y_{i}\right|+C_{3} \sum_{i=1}^{n} p_{i}\left|x_{i-} y_{i}\right|
$$

The arithmetic PWAGE (if $w_{j}=1 / n$, for all $j$ ):

$$
\text { ArithmeticPWAGE }=C_{1}\left(\frac{1}{n} \sum_{j=1}^{n} b_{j}\right)+C_{2} \sum_{i=1}^{n} v_{i}\left|x_{i-} y_{i}\right|+C_{3} \sum_{i=1}^{n} p_{i}\left|x_{i-} y_{i}\right|
$$

- The arithmetic POWAGE operator (if $v_{i}=1 / n$, for all $i$ ):

$$
\text { ArithmeticPOWAGE }=C_{1} \sum_{j=1}^{n} w_{j} b_{j}+C_{2}\left(\frac{1}{n} \sum_{i=1}^{n}\left|x_{i-} y_{i}\right|\right)+C_{3} \sum_{i=1}^{n} p_{i}\left|x_{i-} y_{i}\right|
$$

Many other particular cases can be studied by looking at different expressions of the weighting vectors and the coefficients $C_{1}, C_{2}$ and $C_{3}$. for example:
- If $C_{1}=1$, we obtain the OWAGE operator.

- If $C_{2}=1$, the weighted GHG emission (WGE).

- If $C_{3}=1$, the probabilistic GHG emission (PGE).

- If $C_{1}=0$, the probabilistic weighted averaging GHG emission (PWAGE).

- If $C_{2}=0$, the probabilistic OWA GHG emission (POWAGE).

- If $C_{3}=0$, the OWAWA GHG emission (OWAWAGE) [31].

Example 1. Assume we have the following arguments $A=(60,40,70,20)$ that represent a set of four different gases emissions and the following weighting vector $W=(0.50,0.25,0.15,0.10)$. If we aggregate the WA aggregation, we get the following result:

$W A G E=0.50 \times 60+0.25 \times 40+0.15 \times 70+0.10 \times 20=52.50$,

Now we assume the same arguments and the same weighting vector. If we aggregate OWA aggregation, we get the following result:

$O W A G E=0.50 \times 70+0.25 \times 60+0.15 \times 40+0.10 \times 20=58$. Generalizations with generalized and quasiarithmetic means

Generalization of the OWA operators is possible to do by generalized and quasi-arithmetic averaging aggregation operators that as the most common one generalized OWA (GOWA) [43] and then quasiarithmetic OWA (Quasi-OWA) [11] are formed. These functions apply a general framework including particular cases. The GOWA operator applied to the analysis of gases emissions is called GOWA gases emissions (GOWAGE) and is defined as follows.

Definition 8. A GOWAGE operator of dimension $n$ is a mapping $G O W A: R^{n} \rightarrow R$ that has an associated weighting vector $W$ of dimension $n$ with $\sum_{j=1}^{n} w_{j}=1$ and $w_{j} \in[0,1]$, such that:

$\operatorname{GOWAGE}\left(e_{1}, e_{2}, \ldots, e_{n}\right)=\left(\sum_{j=1}^{n} w_{j} b_{j}^{\lambda}\right)^{1 / \lambda}$

where $b_{j}$ is the $j$ th largest of the $e_{i}$, and $\lambda$ is a parameter such that $\lambda \in(-\infty, \infty)-\{0\}$.

Like the section 3, this operator also has the particular cases of the maximum, the minimum and the generalized mean (GM). Besides, there are some special cases that can be obtained by maneuvering on the values of $\lambda$, such as: 
Table 1 European average GHG emission according to different scenario-expert 1

\begin{tabular}{|c|c|c|c|c|c|c|c|c|c|c|}
\hline Country & Abbreviation & Population & Weight & Scenario 1 & Scenario 2 & Scenario 3 & Scenario 4 & Scenario 5 & Scenario 6 & Scenario 7 \\
\hline Albania & ALB & $2,934,363$ & 0.003959 & 0.21 & 0.18 & 0.26 & 0.25 & 0.31 & 0.19 & 0.24 \\
\hline Andorra & AND & 76,953 & 0.000104 & 0.39 & 0.46 & 0.13 & 0.40 & 0.43 & 0.39 & 0.15 \\
\hline Austria & AUT & $8,751,820$ & 0.011808 & 0.13 & 0.25 & 0.15 & 0.31 & 0.26 & 0.22 & 0.22 \\
\hline Belarus & BLR & $9,452,113$ & 0.012753 & 0.36 & 0.27 & 0.30 & 0.45 & 0.32 & 0.42 & 0.13 \\
\hline Belgium & BEL & $11,498,519$ & 0.015515 & 0.47 & 0.44 & 0.32 & 0.39 & 0.21 & 0.27 & 0.46 \\
\hline Bosnia and Herzegovina & BIH & $3,503,554$ & 0.004727 & 0.23 & 0.34 & 0.38 & 0.14 & 0.44 & 0.28 & 0.24 \\
\hline Bulgaria & BGR & $7,036,848$ & 0.009495 & 0.15 & 0.22 & 0.37 & 0.35 & 0.44 & 0.15 & 0.25 \\
\hline Cyprus & CYP & $1,189,085$ & 0.001604 & 0.47 & 0.48 & 0.47 & 0.15 & 0.14 & 0.37 & 0.13 \\
\hline Czech R & CZE & $10,625,250$ & 0.014336 & 0.15 & 0.42 & 0.39 & 0.37 & 0.14 & 0.50 & 0.47 \\
\hline Denmark & DNK & $5,754,356$ & 0.007764 & 0.24 & 0.35 & 0.13 & 0.17 & 0.49 & 0.25 & 0.18 \\
\hline Estonia & EST & $1,306,788$ & 0.001763 & 0.49 & 0.31 & 0.27 & 0.27 & 0.15 & 0.36 & 0.46 \\
\hline Finland & FIN & $5,542,517$ & 0.007478 & 0.14 & 0.22 & 0.28 & 0.20 & 0.50 & 0.19 & 0.34 \\
\hline France & FRA & $65,233,271$ & 0.088017 & 0.19 & 0.23 & 0.23 & 0.43 & 0.20 & 0.18 & 0.46 \\
\hline Germany & DEU & $82,293,457$ & 0.111035 & 0.16 & 0.49 & 0.47 & 0.29 & 0.26 & 0.17 & 0.22 \\
\hline Greece & GRC & $11,142,161$ & 0.015034 & 0.32 & 0.46 & 0.45 & 0.42 & 0.29 & 0.29 & 0.22 \\
\hline Hungary & HUN & $9,688,847$ & 0.013073 & 0.18 & 0.34 & 0.26 & 0.47 & 0.37 & 0.37 & 0.16 \\
\hline Iceland & ISL & 337,780 & 0.000456 & 0.34 & 0.41 & 0.22 & 0.39 & 0.22 & 0.24 & 0.19 \\
\hline $\mathrm{R}$ Ireland & IRL & $4,803,748$ & 0.006482 & 0.47 & 0.13 & 0.39 & 0.27 & 0.35 & 0.36 & 0.46 \\
\hline Italy & ITA & $59,290,969$ & 0.079999 & 0.44 & 0.14 & 0.50 & 0.20 & 0.49 & 0.19 & 0.23 \\
\hline Kosovo & RKS & $1,808,698$ & 0.002440 & 0.21 & 0.28 & 0.39 & 0.13 & 0.40 & 0.39 & 0.41 \\
\hline Latvia & LVA & $1,929,938$ & 0.002604 & 0.31 & 0.14 & 0.27 & 0.38 & 0.23 & 0.13 & 0.26 \\
\hline Liechtenstein & LIE & 38,155 & 0.000051 & 0.46 & 0.27 & 0.33 & 0.43 & 0.16 & 0.27 & 0.35 \\
\hline Lithuania & LTU & $2,876,475$ & 0.003881 & 0.28 & 0.31 & 0.36 & 0.28 & 0.29 & 0.20 & 0.46 \\
\hline Luxembourg & LUX & 590,321 & 0.000796 & 0.23 & 0.34 & 0.26 & 0.33 & 0.18 & 0.48 & 0.13 \\
\hline Macedonia & MKD & $2,085,051$ & 0.002813 & 0.18 & 0.33 & 0.37 & 0.14 & 0.41 & 0.25 & 0.43 \\
\hline Malta & MLT & 432,089 & 0.000583 & 0.26 & 0.41 & 0.48 & 0.43 & 0.41 & 0.32 & 0.39 \\
\hline Moldova & MDA & $4,041,065$ & 0.005452 & 0.46 & 0.38 & 0.48 & 0.14 & 0.31 & 0.47 & 0.18 \\
\hline Monaco & $\mathrm{MCO}$ & 38,897 & 0.000052 & 0.20 & 0.16 & 0.13 & 0.45 & 0.37 & 0.22 & 0.48 \\
\hline Montenegro & MNE & 629,219 & 0.000849 & 0.28 & 0.47 & 0.19 & 0.13 & 0.20 & 0.18 & 0.44 \\
\hline Netherlands & NLD & $17,084,459$ & 0.023051 & 0.34 & 0.27 & 0.16 & 0.31 & 0.46 & 0.31 & 0.48 \\
\hline Norway & NOR & $5,353,363$ & 0.007223 & 0.23 & 0.27 & 0.36 & 0.18 & 0.32 & 0.28 & 0.35 \\
\hline Poland & POL & $38,104,832$ & 0.051413 & 0.50 & 0.27 & 0.19 & 0.44 & 0.20 & 0.13 & 0.26 \\
\hline Portugal & PRT & $10,291,196$ & 0.013886 & 0.38 & 0.33 & 0.30 & 0.30 & 0.32 & 0.35 & 0.50 \\
\hline Romania & ROU & $19,580,634$ & 0.026419 & 0.20 & 0.33 & 0.29 & 0.14 & 0.16 & 0.46 & 0.20 \\
\hline Russia & RUS & $143,964,709$ & 0.194246 & 0.17 & 0.30 & 0.18 & 0.26 & 0.18 & 0.45 & 0.36 \\
\hline San Marino & SMR & 33,557 & 0.000045 & 0.50 & 0.36 & 0.17 & 0.43 & 0.30 & 0.49 & 0.37 \\
\hline Serbia & SRB & $8,762,027$ & 0.011822 & 0.23 & 0.30 & 0.16 & 0.45 & 0.19 & 0.23 & 0.32 \\
\hline Slovakia & SVK & $5,449,816$ & 0.007353 & 0.48 & 0.49 & 0.30 & 0.30 & 0.43 & 0.26 & 0.39 \\
\hline Slovenia & SVN & $2,081,260$ & 0.002808 & 0.25 & 0.25 & 0.50 & 0.18 & 0.15 & 0.49 & 0.45 \\
\hline Spain & ESP & $46,397,452$ & 0.062602 & 0.17 & 0.13 & 0.26 & 0.18 & 0.20 & 0.44 & 0.43 \\
\hline Sweden & SWE & $9,982,709$ & 0.013469 & 0.44 & 0.29 & 0.30 & 0.37 & 0.45 & 0.32 & 0.48 \\
\hline Switzerland & CHE & $8,544,034$ & 0.011528 & 0.21 & 0.42 & 0.27 & 0.50 & 0.41 & 0.41 & 0.25 \\
\hline Ukraine & UKR & $44,009,214$ & 0.059380 & 0.45 & 0.47 & 0.45 & 0.22 & 0.17 & 0.47 & 0.21 \\
\hline United Kingdom & GBR & $66,573,504$ & 0.089825 & 0.40 & 0.49 & 0.17 & 0.42 & 0.35 & 0.29 & 0.27 \\
\hline Vatican city & VAT & 801 & 0.000001 & 0.23 & 0.28 & 0.16 & 0.27 & 0.37 & 0.23 & 0.18 \\
\hline European average & & $741,145,874$ & 1 & 0.310 & 0.323 & 0.304 & 0.299 & 0.307 & 0.314 & 0.323 \\
\hline
\end{tabular}


Table 2 European average GHG emission according to different scenarios-expert 2

\begin{tabular}{|c|c|c|c|c|c|c|c|}
\hline Abbr. & 1 & 2 & 3 & 4 & 5 & 6 & 7 \\
\hline ALB & 0.22 & 0.48 & 0.39 & 0.27 & 0.17 & 0.35 & 0.26 \\
\hline AND & 0.26 & & 0.49 & 0.29 & 0.18 & 0.22 & 0.14 \\
\hline AUT & 0.45 & 0.20 & 0.39 & 0.21 & 0.13 & 0.47 & 0.35 \\
\hline BLR & 20 & 0.46 & 0.24 & 0.25 & 0.45 & 0.16 & 0.24 \\
\hline BEL & .49 & 0.43 & 0.14 & 0.21 & 0.20 & 0.42 & 0.40 \\
\hline BIH & 48 & 0.48 & 0.15 & 0.43 & 0.39 & 0.33 & 0.26 \\
\hline BGR & 0.37 & 0.23 & 0.42 & 0.16 & 0.38 & 0.39 & 0.29 \\
\hline CYP & & & 0.26 & & & & 0.36 \\
\hline CZE & 0.16 & 0.27 & 0.32 & 0.15 & 0.36 & 0.44 & 0.20 \\
\hline DNK & 25 & 0.18 & 0.32 & 0.16 & 0.39 & 0.29 & 0.45 \\
\hline EST & & 50 & 0.22 & 0.28 & 0.14 & 0.40 & 0.18 \\
\hline FIN & & 49 & 0.29 & 41 & 38 & .50 & 0.35 \\
\hline FRA & & 25 & 19 & 34 & .50 & .20 & 0.26 \\
\hline DEU & & & 0.24 & 0.31 & 0.32 & .44 & 0.13 \\
\hline GRC & & 0.26 & 0.16 & 0.43 & 0.17 & 0.43 & 0.31 \\
\hline HUN & 48 & 0.21 & 0.20 & 0.50 & 0.44 & 0.41 & 0.38 \\
\hline ISL & & & 0.24 & 0.42 & 0.34 & 0.44 & 0.13 \\
\hline IRL & & & 0.13 & 0.23 & 0.25 & 0.50 & 0.25 \\
\hline ITA & 47 & 0.35 & 0.34 & 0.30 & 0.26 & 0.33 & 0.34 \\
\hline RKS & & & & & & & 0.45 \\
\hline LVA & & & & & & & \\
\hline LIE & & & & & & & .29 \\
\hline LTU & & & & & 0.2 & & .50 \\
\hline LUX & & & & 24 & 0.27 & & 0.49 \\
\hline MKD & & & & 46 & 0.45 & 8 & 0.45 \\
\hline MLT & & 22 & 0.20 & 23 & 0.35 & 0.19 & 0.32 \\
\hline MDA & 45 & 0.22 & 0.24 & 0.39 & 0.39 & 0.44 & 0.25 \\
\hline $\mathrm{MCO}$ & & & 0.24 & 0.50 & 0.26 & .42 & 0.28 \\
\hline MNE & & & 0.39 & 0.40 & 0.20 & 0.27 & 0.32 \\
\hline NLD & & & & & 0.44 & 0.13 & 0.27 \\
\hline NOR & & & 0.28 & & 0.44 & & 0.26 \\
\hline POL & & & & & & & \\
\hline PRT & & & & & & & \\
\hline ROU & & & & & & & \\
\hline RUS & & & & & & & 0.47 \\
\hline SMR & & & 0.28 & 0.28 & 03 & 0.49 & 0.21 \\
\hline SRB & & & 0.21 & 01 & 0.28 & 5 & 0.49 \\
\hline SVK & 0.13 & & 0.46 & 0.22 & 0.26 & 0.27 & 0.36 \\
\hline SVN & & & 0.16 & 025 & 0.45 & 0.49 & 0.41 \\
\hline ESP & & & 0.25 & 0.16 & 0.42 & 0.31 & 0.50 \\
\hline SWE & & & 0.47 & 0.38 & 0.27 & 0.37 & 0.46 \\
\hline CHE & & & 0.28 & & 0.31 & 0.43 & 0.43 \\
\hline UKR & & & & & 0.20 & 0.36 & 0.15 \\
\hline & & & 0.21 & 0. & 0.42 & 0.31 & 0.44 \\
\hline VAT & & & & & & 0.50 & 0.19 \\
\hline EA. & 0.319 & 0.321 & 0.267 & 0.301 & 0.320 & 0.357 & 0.316 \\
\hline
\end{tabular}

Abbr.: Abbreviation, EA.: Europen average

- If $\lambda=1$, the usual OWAGE operator.

- If $\lambda \rightarrow 0$, the ordered weighted geometric average gases emissions (OWGAGE).

- If $\lambda=2$, the ordered weighted quadratic average gases emissions (OWQAGE).

- If $\lambda=-1$, the ordered weighted harmonic average gases emissions (OWHAGE).
Table 3 European average GHG emission according to different scenarios-expert 3

\begin{tabular}{|c|c|c|c|c|c|c|c|}
\hline Abbr. & 1 & 2 & 3 & 4 & 5 & 6 & 7 \\
\hline ALB & 0.29 & 0.31 & 0.37 & 0.21 & 0.17 & 0.35 & 0.26 \\
\hline AND & 0.36 & 0.36 & 0.24 & 0.29 & 0.22 & 0.28 & 0.27 \\
\hline AUT & 0.22 & 0.29 & 0.35 & 0.35 & 0.37 & 0.29 & 0.38 \\
\hline BLR & 0.32 & 0.24 & 0.18 & 0.23 & 0.22 & 0.37 & 0.32 \\
\hline BEL & 0.22 & 0.19 & 0.37 & 0.18 & 0.19 & 0.25 & 0.34 \\
\hline $\mathrm{BIH}$ & 0.38 & 0.19 & 0.38 & 0.32 & 0.32 & 0.26 & 0.30 \\
\hline BGR & 0.28 & 0.25 & 0.15 & 0.37 & 0.28 & 0.21 & 0.38 \\
\hline CYP & 0.36 & 0.19 & 0.26 & 0.26 & 0.17 & 0.33 & 0.29 \\
\hline CZE & 0.19 & 0.32 & 0.23 & 0.16 & 0.23 & 0.27 & 0.30 \\
\hline DNK & 0.29 & 0.29 & 0.15 & 0.38 & 0.36 & 0.15 & 0.27 \\
\hline EST & 22 & 0.20 & 0.36 & 0.23 & 0.33 & 0.26 & 0.35 \\
\hline FIN & 24 & 0.36 & 0.32 & 0.16 & 0.33 & 0.34 & 0.33 \\
\hline FRA & 35 & 0.34 & 0.24 & 0.36 & 0.28 & 0.17 & 0.26 \\
\hline DEU & 0.38 & 0.34 & 0.38 & 0.37 & 0.15 & 0.28 & 0.34 \\
\hline GRC & & 0.20 & 0.28 & 0.18 & 0.31 & 0.17 & 0.25 \\
\hline HUN & & 0.26 & 0.38 & 0.22 & 0.38 & 0.17 & 0.37 \\
\hline ISL & 0.23 & 0.18 & 0.16 & 0.22 & 0.37 & 0.18 & 0.24 \\
\hline IRL & 0.28 & 0.21 & 0.38 & 0.33 & 0.28 & 0.30 & 0.36 \\
\hline ITA & 0.18 & 0.34 & 0.23 & 0.16 & 0.38 & 0.16 & 0.28 \\
\hline RKS & & 0.16 & 0.34 & 0.17 & 0.17 & 0.21 & 0.20 \\
\hline & & & 20 & 0.24 & 15 & & 0.30 \\
\hline LIE & & 32 & 0.31 & 0.22 & 0.36 & .27 & 0.26 \\
\hline LTU & & 0.24 & 0.32 & 0.15 & 0.28 & .36 & 0.33 \\
\hline LUX & & 0.21 & 0.19 & 0.21 & 0.23 & 0.29 & 0.21 \\
\hline MKD & & 35 & 0.35 & 0.25 & 0.16 & 0.35 & 0.27 \\
\hline MLT & & 0.34 & 0.23 & 0.25 & 0.18 & 0.29 & 0.16 \\
\hline MDA & & 0.20 & 0.26 & 0.16 & 0.23 & 0.23 & 0.34 \\
\hline MCO & & 0.17 & 0.32 & 0.36 & 0.27 & 0.38 & 0.20 \\
\hline MNE & & 0.26 & 0.18 & 0.24 & 0.24 & 0.31 & 0.28 \\
\hline NLD & & 0.18 & 0.22 & 0.30 & 0.32 & 0.20 & 0.34 \\
\hline NOR & & 0.17 & 0.29 & 0.18 & 0.26 & 0.28 & 0.22 \\
\hline POL & & 0.22 & 0.34 & 0.23 & 0.29 & 0.23 & 0.29 \\
\hline & & & 0.25 & 0.21 & 0.19 & .27 & 0.20 \\
\hline & & & & & 0.24 & & 0.34 \\
\hline RUS & & & 0.34 & 0.33 & 0.35 & 0.18 & 0.17 \\
\hline SMR & 0.16 & & 0.30 & 0.20 & 0.37 & 0.16 & 0.16 \\
\hline SRB & 0.15 & 0.27 & 0.22 & 0.21 & 0.27 & 0.16 & 0.34 \\
\hline SVK & 0.23 & 0.33 & 0.15 & 0.33 & 0.30 & 0.21 & 0.19 \\
\hline SVN & & & 0.24 & 0.22 & 0.36 & 0.26 & 0.32 \\
\hline ESP & & 0.37 & 0.21 & 0.21 & 0.22 & 0.27 & 0.20 \\
\hline SWE & & 0.38 & 0.33 & 0.33 & 0.25 & 0.26 & 0.20 \\
\hline CHE & & & 0.30 & 0.35 & 0.24 & 0.30 & 0.34 \\
\hline UKR & 0.3 & 0.33 & 0.33 & 0.15 & 0.32 & 0.30 & 0.36 \\
\hline GBR & 0.3 & & 0.38 & 0.15 & 0.23 & 0.23 & 0.29 \\
\hline VAT & & & 0.15 & 0.26 & 0.31 & 0.20 & 0.26 \\
\hline EA. & 0.264 & 0.271 & 0.276 & 0.248 & 0.270 & 0.254 & 0.281 \\
\hline
\end{tabular}

Quasi-arithmetic OWA gases emissions (QuasiOWAGE) operator is the other generalization that uses the quasi-arithmetic means instead of the generalized means. So, it replaces the parameter $\lambda$ by a strictly continuous monotonic function $g$.

Definition 9. A Quasi-OWAGE operator of dimension $n$ is a mapping Quasi-OWAGE: $R^{n} \rightarrow R$ that has an associated weighting vector $W$ of dimension $n$ with $\sum_{j=1}^{n} w_{j}=1$ and $w_{j} \in[0,1]$, then: 
Table 4 European average GHG emission according to different scenarios-expert 4

\begin{tabular}{|c|c|c|c|c|c|c|c|}
\hline Abbr. & 1 & 2 & 3 & 4 & 5 & 6 & 7 \\
\hline ALB & 0.33 & 0.36 & 0.28 & 0.25 & 0.29 & 0.34 & 0.19 \\
\hline AND & 0.21 & 0.28 & 0.25 & 0.35 & 0.24 & 0.39 & 0.34 \\
\hline AUT & 0.38 & 0.38 & 0.22 & 0.35 & 0.39 & 0.28 & 0.28 \\
\hline BLR & 0.39 & 0.48 & 0.34 & 0.23 & 0.26 & 0.41 & 0.26 \\
\hline BEL & 0.42 & 0.25 & 0.47 & 0.33 & 0.44 & 0.22 & 0.29 \\
\hline BIH & 0.37 & 0.44 & 0.44 & 0.32 & 0.32 & 0.48 & 0.23 \\
\hline BGR & 0.31 & 0.38 & 0.45 & 0.38 & 0.32 & 0.49 & 0.24 \\
\hline CYP & 0.28 & 0.28 & 0.27 & 0.34 & 0.32 & 0.31 & 0.34 \\
\hline CZE & 0.26 & 0.48 & 0.23 & 0.32 & 0.45 & 0.49 & 0.38 \\
\hline DNK & 0.29 & 0.49 & 0.47 & 0.26 & 0.26 & 0.40 & 0.32 \\
\hline EST & 0.32 & 0.36 & 0.42 & 0.27 & 0.34 & 0.26 & 0.33 \\
\hline FIN & 0.48 & 0.38 & 0.26 & 0.45 & 0.47 & 0.39 & 0.34 \\
\hline FRA & 0.38 & 0.28 & 0.29 & 0.39 & 0.37 & 0.40 & 0.46 \\
\hline DEU & 0.24 & 0.26 & 0.22 & 0.26 & 0.27 & 0.27 & 0.45 \\
\hline GRC & 0.48 & 0.32 & 0.37 & 0.27 & 0.28 & 0.41 & 0.45 \\
\hline HUN & 0.44 & 0.36 & 0.23 & 0.26 & 0.34 & 0.25 & 0.27 \\
\hline ISL & 0.31 & 0.29 & 0.32 & 0.39 & 0.19 & 0.27 & 0.28 \\
\hline IRL & 0.46 & 0.22 & 0.30 & 0.29 & 0.30 & 0.43 & 0.48 \\
\hline ITA & 0.31 & 0.38 & 0.40 & 0.41 & 0.42 & 0.28 & 0.41 \\
\hline RKS & 0.22 & 0.34 & 0.31 & 0.25 & 0.32 & 0.37 & 0.39 \\
\hline LVA & 0.31 & 0.49 & 0.35 & 0.30 & 0.42 & 0.31 & 0.38 \\
\hline LIE & 0.43 & 0.22 & 0.31 & 0.29 & 0.45 & 0.22 & 0.22 \\
\hline LTU & 0.49 & 0.35 & 0.42 & 0.29 & 0.32 & 0.40 & 0.34 \\
\hline LUX & 0.36 & 0.25 & 0.30 & 0.29 & 0.36 & 0.41 & 0.28 \\
\hline MKD & 0.44 & 0.31 & 0.40 & 0.37 & 0.46 & 0.39 & 0.42 \\
\hline MLT & 0.41 & 0.34 & 0.32 & 0.35 & 0.36 & 0.44 & 0.43 \\
\hline MDA & 0.43 & 0.35 & 0.43 & 0.49 & 0.37 & 0.44 & 0.39 \\
\hline MCO & 0.44 & 0.19 & 0.37 & 0.36 & 0.26 & 0.29 & 0.18 \\
\hline MNE & 0.34 & 0.32 & 0.27 & 0.14 & 0.28 & 0.32 & 0.41 \\
\hline NLD & 0.30 & 0.37 & 0.35 & 0.38 & 0.49 & 0.35 & 0.22 \\
\hline NOR & 0.49 & 0.25 & 0.39 & 0.40 & 0.41 & 0.32 & 0.38 \\
\hline POL & 0.44 & 0.36 & 0.32 & 0.28 & 0.48 & 0.36 & 0.42 \\
\hline PRT & 0.38 & 0.45 & 0.49 & 0.33 & 0.27 & 0.41 & 0.23 \\
\hline ROU & 0.40 & 0.38 & 0.35 & 0.32 & 0.29 & 0.27 & 0.32 \\
\hline RUS & 0.35 & 0.27 & 0.32 & 0.33 & 0.31 & 0.27 & 0.40 \\
\hline SMR & 0.27 & 0.40 & 0.36 & 0.27 & 0.44 & 0.30 & 0.39 \\
\hline SRB & 0.49 & 0.28 & 0.27 & 0.38 & 0.45 & 0.38 & 0.44 \\
\hline SVK & 0.37 & 0.31 & 0.42 & 0.30 & 0.41 & 0.42 & 0.42 \\
\hline SVN & 0.31 & 0.35 & 0.36 & 0.43 & 0.43 & 0.30 & 0.25 \\
\hline ESP & 0.44 & 0.41 & 0.24 & 0.25 & 0.34 & 0.46 & 0.27 \\
\hline SWE & 0.28 & 0.45 & 0.49 & 0.39 & 0.24 & 0.49 & 0.42 \\
\hline CHE & 0.24 & 0.39 & 0.30 & 0.41 & 0.30 & 0.27 & 0.46 \\
\hline UKR & 0.34 & 0.40 & 0.42 & 0.25 & 0.29 & 0.34 & 0.42 \\
\hline GBR & 0.26 & 0.39 & 0.37 & 0.43 & 0.38 & 0.30 & 0.27 \\
\hline VAT & 0.18 & 0.12 & 0.21 & 0.19 & 0.23 & 0.15 & 0.20 \\
\hline EA. & 0.366 & 0.348 & 0.342 & 0.330 & 0.359 & 0.353 & 0.351 \\
\hline
\end{tabular}

Quasi-OWAGE $\left(e_{1}, e_{2}, \ldots, e_{n}\right)=g^{-1}\left(\sum_{j=1}^{n} w_{j} g\left(b_{(j)}\right)\right)$

where $b_{j}$ is the $j$ th largest of the $e_{i}$ and $g$ is strictly continuous monotonic function.

\section{Illustrative example}

In this section through a numerical example we try to show the applicability of OWA operators. This work concentrates on the calculation of different OWA operators' aggregation on green-house gases emission of European countries and makes a comparison on them to gain a clear decision about their possible future scenarios. To this end and with the purpose of giving a correct overview to solve the problem, a group of four experts analyses the information in seven scenarios. This step by step process can be explained as follows.

Step 1: Four experts analyze the green-house gases emission of European countries in seven possible scenarios in future based on the environmental and economic situation of the mentioned country. Table 1 , 2, 3 and 4 represent the opinions of the experts. Table 2,3 and 4 are the same as 1 but to avoid repeating, we summarized them to a short form.

Step 2: The next step belongs to unify the experts' opinions to achieve to a collective result that cover all the information. To this end, it is necessary to assign the degree of importance to each of the experts: $Z=(0.4,0.35,0.15,0.1)$. Table 5 reports the collective results of each country.

Step 3: Based on the objective of this work it is necessary to assign weighting vectors to consider subjective and objective information and an attitudinal character that underestimates the results.

- OWA:

$W=(0.1 ; 0.15 ; 0.1 ; 0.2 ; 0.15 ; 0.25 ; 0.05)$

- Weighted average:

$V=(0.2 ; 0.15 ; 0.1 ; 0.15 ; 0.1 ; 0.1 ; 0.2)$

- Probability:

$P=(0.1 ; 0.2 ; 0.1 ; 0.1 ; 0.2 ; 0.1 ; 0.2)$

- OWAWA: $\beta=0.3$

- POWAWA: $C_{1}=0.2 ; C_{2}=0.4 ; C_{3}=0.4$

- $U=(0.6 ; 0.2 ; 0.4 ; 0.7 ; 0.3 ; 0.4 ; 0.8)$

Step 4: Present the obtained results of the average green-house gases for each country for the OWAGE, WAGE, OWAWAGE, IOWAGE, IOWAWAGE, POWAWAGE and IPOWAWAGE. Table 6 dedicates to the aggregated results.

Step 5: Rank the countries from the lowest to the highest in each of the operators to draw some conclusions. Table 7 presents the results of this ranking based on the abbreviation of the name of each country.

\section{Conclusions}

The purpose of this study is to concentrate on the analysis of the use of the aggregation operators in the calculation of GHG emission with the aim of developing better decision-making techniques. In this study we reviewed some of the important operators of the family of OWA. This review started with simple WA and continued with OWA operator. 


\begin{tabular}{|c|c|c|c|c|c|c|c|}
\hline Country & Scenario 1 & Scenario 2 & Scenario 3 & Scenario 4 & Scenario 5 & Scenario 6 & Scenario 7 \\
\hline Albania & 0.24 & 0.32 & 0.32 & 0.25 & 0.24 & 0.29 & 0.25 \\
\hline Andorra & 0.32 & 0.40 & 0.28 & 0.34 & 0.29 & 0.31 & 0.18 \\
\hline Austria & 0.28 & 0.25 & 0.27 & 0.29 & 0.24 & 0.32 & 0.30 \\
\hline Belarus & 0.30 & 0.35 & 0.27 & 0.33 & 0.34 & 0.32 & 0.21 \\
\hline Belgium & 0.43 & 0.38 & 0.28 & 0.29 & 0.23 & 0.31 & 0.40 \\
\hline Bosnia and Herzegovina & 0.35 & 0.38 & 0.31 & 0.29 & 0.39 & 0.31 & 0.26 \\
\hline Bulgaria & 0.26 & 0.24 & 0.36 & 0.29 & 0.38 & 0.28 & 0.28 \\
\hline Cyprus & 0.37 & 0.37 & 0.35 & 0.21 & 0.20 & 0.31 & 0.26 \\
\hline Czech R & 0.17 & 0.36 & 0.33 & 0.26 & 0.26 & 0.44 & 0.34 \\
\hline Denmark & 0.26 & 0.30 & 0.23 & 0.21 & 0.41 & 0.26 & 0.30 \\
\hline Estonia & 0.32 & 0.37 & 0.28 & 0.27 & 0.19 & 0.35 & 0.33 \\
\hline Finland & 0.25 & 0.35 & 0.29 & 0.29 & 0.43 & 0.34 & 0.34 \\
\hline France & 0.29 & 0.26 & 0.22 & 0.38 & 0.33 & 0.21 & 0.36 \\
\hline Germany & 0.19 & 0.43 & 0.35 & 0.31 & 0.27 & 0.29 & 0.23 \\
\hline Greece & 0.27 & 0.34 & 0.32 & 0.37 & 0.25 & 0.33 & 0.28 \\
\hline Hungary & 0.32 & 0.28 & 0.25 & 0.42 & 0.39 & 0.34 & 0.28 \\
\hline Iceland & 0.28 & 0.34 & 0.23 & 0.38 & 0.28 & 0.30 & 0.19 \\
\hline $\mathrm{R}$ Ireland & 0.32 & 0.24 & 0.29 & 0.27 & 0.30 & 0.41 & 0.37 \\
\hline Italy & 0.40 & 0.27 & 0.39 & 0.25 & 0.39 & 0.24 & 0.29 \\
\hline Kosovo & 0.32 & 0.33 & 0.30 & 0.23 & 0.34 & 0.31 & 0.39 \\
\hline Latvia & 0.29 & 0.19 & 0.29 & 0.39 & 0.30 & 0.24 & 0.28 \\
\hline Liechtenstein & 0.39 & 0.31 & 0.26 & 0.29 & 0.25 & 0.27 & 0.30 \\
\hline Lithuania & 0.26 & 0.34 & 0.29 & 0.22 & 0.29 & 0.34 & 0.44 \\
\hline Luxembourg & 0.27 & 0.31 & 0.21 & 0.28 & 0.24 & 0.40 & 0.28 \\
\hline Macedonia & 0.30 & 0.27 & 0.38 & 0.29 & 0.39 & 0.32 & 0.41 \\
\hline Malta & 0.34 & 0.33 & 0.33 & 0.33 & 0.35 & 0.28 & 0.34 \\
\hline Moldova & 0.43 & 0.29 & 0.36 & 0.27 & 0.33 & 0.42 & 0.25 \\
\hline Monaco & 0.33 & 0.22 & 0.22 & 0.45 & 0.31 & 0.32 & 0.34 \\
\hline Montenegro & 0.25 & 0.34 & 0.27 & 0.24 & 0.21 & 0.25 & 0.37 \\
\hline Netherlands & 0.33 & 0.22 & 0.20 & 0.30 & 0.44 & 0.23 & 0.36 \\
\hline Norway & 0.25 & 0.23 & 0.32 & 0.25 & 0.36 & 0.28 & 0.30 \\
\hline Poland & 0.38 & 0.22 & 0.25 & 0.32 & 0.35 & 0.26 & 0.25 \\
\hline Portugal & 0.39 & 0.33 & 0.36 & 0.27 & 0.31 & 0.33 & 0.38 \\
\hline Romania & 0.32 & 0.32 & 0.30 & 0.26 & 0.18 & 0.36 & 0.21 \\
\hline Russia & 0.20 & 0.33 & 0.28 & 0.32 & 0.24 & 0.35 & 0.37 \\
\hline San Marino & 0.33 & 0.36 & 0.25 & 0.33 & 0.35 & 0.42 & 0.28 \\
\hline Serbia & 0.32 & 0.29 & 0.20 & 0.31 & 0.26 & 0.31 & 0.39 \\
\hline Slovakia & 0.31 & 0.42 & 0.35 & 0.28 & 0.35 & 0.27 & 0.35 \\
\hline Slovenia & 0.32 & 0.32 & 0.33 & 0.24 & 0.31 & 0.44 & 0.40 \\
\hline Spain & 0.23 & 0.29 & 0.25 & 0.18 & 0.29 & 0.37 & 0.40 \\
\hline Sweden & 0.34 & 0.35 & 0.38 & 0.37 & 0.34 & 0.35 & 0.43 \\
\hline Switzerland & 0.31 & 0.36 & 0.28 & 0.41 & 0.34 & 0.39 & 0.35 \\
\hline Ukraine & 0.43 & 0.41 & 0.32 & 0.26 & 0.22 & 0.39 & 0.23 \\
\hline United Kingdom & 0.40 & 0.40 & 0.24 & 0.38 & 0.36 & 0.29 & 0.33 \\
\hline Vatican city & 0.21 & 0.24 & 0.16 & 0.24 & 0.36 & 0.31 & 0.20 \\
\hline European average & 0.31 & 0.32 & 0.29 & 0.30 & 0.31 & 0.32 & 0.32 \\
\hline
\end{tabular}

Moreover, we also analyzed some operators that form by combination of two or more aggregation operators. So, these operators are, IOWAGE, OWAWAGE, IOWAWAGE, POWAWAGE and IPOWAWAGE.

In addition, through these formulations, we found some particular cases in either IOWAWAGE or POWAWAGE operators such as, olympicIOWAWAGE, S-IOWAWAGE, centeredIOWAWAGE, maximum, minimum and arithmetic probabilistic weighted average, and arithmetic probabilistic ordered weighted average.
Furthermore, some other generalizations are developed by using generalized and quasi-arithmetic means obtaining the GOWAGE and the QuasiOWAGE operators.

The study provides a simple example to review the function of two simple aggregations operators of average green-house gases emission. During this example we review weighted average gases emission (WAGE) and ordered weighted average gases emission (OWAGE) to represent the difference between the result of the calculation based on these operators. 


\begin{tabular}{|c|c|c|c|c|c|c|c|}
\hline Country & WAGE & OWAGE & OWAWAGE & IOWAGE & IOWAWAGE & POWAWAGE & IPOWAWAGE \\
\hline Albania & 0.274 & 0.268 & 0.267 & 0.267 & 0.267 & 0.269 & 0.269 \\
\hline Andorra & 0.320 & 0.310 & 0.304 & 0.300 & 0.301 & 0.303 & 0.301 \\
\hline Austria & 0.282 & 0.317 & 0.291 & 0.279 & 0.280 & 0.285 & 0.277 \\
\hline Belarus & 0.317 & 0.333 & 0.308 & 0.307 & 0.300 & 0.306 & 0.301 \\
\hline Belgium & 0.319 & 0.276 & 0.328 & 0.308 & 0.337 & 0.329 & 0.335 \\
\hline Bosnia and Herzegovina & 0.330 & 0.339 & 0.328 & 0.330 & 0.325 & 0.329 & 0.327 \\
\hline Bulgaria & 0.298 & 0.334 & 0.304 & 0.316 & 0.299 & 0.304 & 0.300 \\
\hline Cyprus & 0.288 & 0.288 & 0.294 & 0.276 & 0.291 & 0.292 & 0.289 \\
\hline Czech R & 0.322 & 0.280 & 0.292 & 0.310 & 0.301 & 0.300 & 0.306 \\
\hline Denmark & 0.278 & 0.307 & 0.287 & 0.293 & 0.282 & 0.292 & 0.289 \\
\hline Estonia & 0.302 & 0.304 & 0.307 & 0.284 & 0.301 & 0.304 & 0.300 \\
\hline Finland & 0.331 & 0.320 & 0.320 & 0.339 & 0.326 & 0.328 & 0.332 \\
\hline France & 0.286 & 0.315 & 0.306 & 0.294 & 0.299 & 0.304 & 0.300 \\
\hline Germany & 0.303 & 0.287 & 0.285 & 0.286 & 0.285 & 0.291 & 0.290 \\
\hline Greece & 0.318 & 0.270 & 0.295 & 0.304 & 0.305 & 0.297 & 0.304 \\
\hline Hungary & 0.343 & 0.333 & 0.327 & 0.342 & 0.330 & 0.327 & 0.329 \\
\hline Iceland & 0.303 & 0.281 & 0.280 & 0.284 & 0.281 & 0.280 & 0.280 \\
\hline Ireland & 0.316 & 0.312 & 0.314 & 0.321 & 0.316 & 0.312 & 0.314 \\
\hline Italy & 0.303 & 0.316 & 0.318 & 0.324 & 0.320 & 0.318 & 0.319 \\
\hline Kosovo & 0.305 & 0.301 & 0.314 & 0.313 & 0.318 & 0.319 & 0.321 \\
\hline Latvia & 0.284 & 0.337 & 0.300 & 0.293 & 0.287 & 0.291 & 0.282 \\
\hline Liechtenstein & 0.289 & 0.286 & 0.300 & 0.284 & 0.299 & 0.297 & 0.296 \\
\hline Lithuania & 0.303 & 0.317 & 0.318 & 0.307 & 0.315 & 0.322 & 0.320 \\
\hline Luxembourg & 0.297 & 0.265 & 0.277 & 0.281 & 0.281 & 0.278 & 0.281 \\
\hline Macedonia & 0.328 & 0.349 & 0.340 & 0.349 & 0.340 & 0.342 & 0.342 \\
\hline Malta & 0.320 & 0.296 & 0.319 & 0.326 & 0.328 & 0.322 & 0.328 \\
\hline Moldova & 0.344 & 0.304 & 0.323 & 0.344 & 0.335 & 0.323 & 0.330 \\
\hline Monaco & 0.320 & 0.319 & 0.318 & 0.318 & 0.318 & 0.313 & 0.313 \\
\hline Montenegro & 0.263 & 0.323 & 0.296 & 0.258 & 0.277 & 0.293 & 0.280 \\
\hline Netherlands & 0.288 & 0.297 & 0.301 & 0.310 & 0.305 & 0.304 & 0.307 \\
\hline Norway & 0.282 & 0.283 & 0.280 & 0.300 & 0.286 & 0.284 & 0.288 \\
\hline Poland & 0.288 & 0.286 & 0.291 & 0.297 & 0.294 & 0.288 & 0.290 \\
\hline Portugal & 0.324 & 0.325 & 0.337 & 0.329 & 0.338 & 0.336 & 0.337 \\
\hline Romania & 0.289 & 0.289 & 0.280 & 0.269 & 0.274 & 0.274 & 0.270 \\
\hline Russia & 0.304 & 0.301 & 0.300 & 0.294 & 0.298 & 0.302 & 0.300 \\
\hline San Marino & 0.348 & 0.320 & 0.324 & 0.336 & 0.329 & 0.326 & 0.330 \\
\hline Serbia & 0.293 & 0.292 & 0.304 & 0.289 & 0.303 & 0.303 & 0.302 \\
\hline Slovakia & 0.321 & 0.290 & 0.320 & 0.322 & 0.330 & 0.329 & 0.335 \\
\hline Slovenia & 0.335 & 0.364 & 0.342 & 0.337 & 0.334 & 0.341 & 0.336 \\
\hline Spain & 0.285 & 0.294 & 0.291 & 0.290 & 0.290 & 0.295 & 0.294 \\
\hline Sweden & 0.356 & 0.359 & 0.364 & 0.360 & 0.365 & 0.365 & 0.365 \\
\hline Switzerland & 0.361 & 0.336 & 0.345 & 0.350 & 0.350 & 0.347 & 0.349 \\
\hline Ukraine & 0.330 & 0.281 & 0.312 & 0.306 & 0.319 & 0.311 & 0.316 \\
\hline United Kingdom & 0.342 & 0.354 & 0.353 & 0.333 & 0.347 & 0.351 & 0.347 \\
\hline Vatican city & 0.264 & 0.283 & 0.251 & 0.265 & 0.246 & 0.252 & 0.249 \\
\hline European average & 0.310 & 0.321 & 0.314 & 0.309 & 0.310 & 0.313 & 0.310 \\
\hline
\end{tabular}

We also analyzed the applicability of these approaches for the process of decision-making problem in GHG emission. To achieve to this aim, we implement an illustrative example regarding the calculation of the average of green-house gases emission among European countries. To this end we collect the opinions of the four experts in this area in seven various scenarios in a multi-person analysis. Based on this example, and through five steps we obtain the final table that demonstrate comprehensively the situation of the European countries in a descending trend based on the results of different aggregation operators that can occur according to different scenarios between the minimum and maximum results.

In the future research, by using the different aggregation operators such as logarithmic [1], heavy $[19,20]$, Bonferroni [5] and prioritized [2], we calculate the average GHG emission in a wide range of scenarios among the countries also among different continents. 


\begin{tabular}{|c|c|c|c|c|c|c|c|}
\hline Rank & WAGE & OWAGE & OWAWAGE & IOWAGE & IOWAWAGE & POWAWAGE & IPOWAWAGE \\
\hline 1 & MNE & LUX & VAT & MNE & VAT & VAT & VAT \\
\hline 2 & VAT & ALB & ALB & VAT & ALB & ALB & ALB \\
\hline 3 & ALB & GRC & LUX & ALB & ROU & ROU & ROU \\
\hline 4 & DNK & BEL & ROU & ROU & MNE & LUX & AUT \\
\hline 5 & AUT & CZE & NOR & CYP & AUT & ISL & MNE \\
\hline 6 & NOR & UKR & ISL & AUT & ISL & NOR & ISL \\
\hline 7 & LVA & ISL & DEU & LUX & LUX & AUT & LUX \\
\hline 8 & ESP & NOR & DNK & LIE & DNK & POL & LVA \\
\hline 9 & FRA & VAT & POL & EST & DEU & DEU & NOR \\
\hline 10 & NLD & POL & ESP & ISL & NOR & LVA & DNK \\
\hline 11 & POL & LIE & AUT & DEU & LVA & CYP & CYP \\
\hline 12 & CYP & DEU & CZE & SRB & ESP & DNK & POL \\
\hline 13 & ROU & CYP & CYP & ESP & CYP & MNE & DEU \\
\hline 14 & LIE & ROU & GRC & DNK & POL & ESP & ESP \\
\hline 15 & SRB & SVK & MNE & LVA & RUS & LIE & LIE \\
\hline 16 & LUX & SRB & LIE & FRA & BGR & GRC & FRA \\
\hline 17 & BGR & ESP & LVA & RUS & LIE & CZE & RUS \\
\hline 18 & EST & MLT & RUS & POL & FRA & RUS & BGR \\
\hline 19 & ITA & NLD & NLD & AND & BLR & AND & EST \\
\hline 20 & LTU & RUS & AND & NOR & AND & SRB & AND \\
\hline 21 & ISL & RKS & SRB & GRC & EST & BGR & BLR \\
\hline 22 & DEU & EST & BGR & UKR & CZE & NLD & SRB \\
\hline 23 & RUS & MDA & FRA & LTU & SRB & FRA & GRC \\
\hline 24 & RKS & DNK & EST & BLR & NLD & EST & CZE \\
\hline 25 & IRL & AND & BLR & BEL & GRC & BLR & NLD \\
\hline 26 & BLR & IRL & UKR & NLD & LTU & UKR & $\mathrm{MCO}$ \\
\hline 27 & GRC & FRA & IRL & CZE & IRL & IRL & IRL \\
\hline 28 & BEL & ITA & RKS & RKS & RKS & $\mathrm{MCO}$ & UKR \\
\hline 29 & AND & AUT & ITA & BGR & $\mathrm{MCO}$ & ITA & ITA \\
\hline 30 & MCO & LTU & LTU & $\mathrm{MCO}$ & UKR & RKS & LTU \\
\hline 31 & MLT & $\mathrm{MCO}$ & $\mathrm{MCO}$ & IRL & ITA & LTU & RKS \\
\hline 32 & SVK & FIN & MLT & SVK & $\mathrm{BIH}$ & MLT & BIH \\
\hline 33 & CZE & SMR & FIN & ITA & FIN & MDA & MLT \\
\hline 34 & PRT & MNE & SVK & MLT & MLT & SMR & HUN \\
\hline 35 & MKD & PRT & MDA & PRT & SMR & HUN & SMR \\
\hline 36 & $\mathrm{BIH}$ & BLR & SMR & BIH & SVK & FIN & MDA \\
\hline 37 & UKR & HUN & HUN & GBR & HUN & SVK & FIN \\
\hline 38 & FIN & BGR & BIH & SMR & SVN & BEL & SVK \\
\hline 39 & SVN & CHE & BEL & SVN & MDA & BIH & BEL \\
\hline 40 & GBR & LVA & PRT & FIN & BEL & PRT & SVN \\
\hline 41 & HUN & $\mathrm{BIH}$ & MKD & HUN & PRT & SVN & PRT \\
\hline 42 & MDA & MKD & SVN & MDA & MKD & MKD & MKD \\
\hline 43 & SMR & GBR & CHE & MKD & GBR & CHE & GBR \\
\hline 44 & SWE & SWE & GBR & CHE & CHE & GBR & CHE \\
\hline 45 & CHE & SVN & SWE & SWE & SWE & SWE & SWE \\
\hline
\end{tabular}

\section{References}

[1] V.G. Alfaro-García, J.M. Merigó, A.M. Gil-Lafuente and J. Kacprzyk, Logarithmic aggregation operators and distance measures, International Journal of Intelligent Systems, 33(2018), 1488-1506.

[2] E. Avilés-Ochoa, E. León-Castro, L.A. Pérez-Arellano and J.M. Merigó, Government transparency measurement through prioritized distance operators, Journal of Intelligent \& Fuzzy Systems, 34(2018), 2783-2794.

[3] G. Beliakov, A. Pradera and T. Calvo, Aggregation functions: A guide for practitioners, Springer-Verlag, Berlin, 2007.

[4] P. Bhattacharyya, K.S. Roy, S. Neogi, T.K. Adhya, K.S. Rao and M.C. Manna, Effects of rice straw and nitrogen fertilization on greenhouse gas emissions and carbon storage in tropical flooded soil planted with rice, Soil and Tillage Research, 124(2012), 119-130.
[5] F. Blanco-Mesa, J.M. Merigó and J. Kacprzyk, Bonferroni means with distance measures and the adequacy coefficient in entrepreneurial group theory, Knowledge-Based Systems, 111(2016), 217-227.

[6] F. Blanco-Mesa, J.M. Merigó and A.M. Gil-Lafuente, Fuzzy decisión making: a bibliometric-based review, Journal of Intelligent \& Fuzzy Systems, 32(2017), 2033-2050.

[7] M. Casanovas, A. Torres-Martinez and J.M. Merigo, Decision making in reinsurance with induced OWA operators and Minkowski distances, Cybernetics \& Systems, 47(2016), 460-477.

[8] S.J. Chen and S.M. Chen, A new method for handling multicriteria fuzzy decision-making problems using FN-IOWA operators, Cybernetics \& Systems, 34(2003), 109-137.

[9] A. Emrouznejad and M. Marra, Ordered weighted averaging operators 1988-2014: A citation-based literature survey, International Journal of Intelligent Systems, 29(2014), 9941014. 
[10] D.J. Flower and J.G. Sanjayan, Green house gas emissions due to concrete manufacture, International Journal of Life Cycle Assessment, 12(2007), 282.

[11] J. Fodor, J.L. Marichal and M. Roubens, Characterization of the ordered weighted averaging operators, IEEE Transactions on Fuzzy Systems, 3(1995), 236-240.

[12] T.J. Hammons, Impact of electric power generation on green house gas emissions in Europe: Russia, Greece, Italy and views of the EU Power Plant Supply Industry-a critical analysis, International Journal of Electrical Power \& Energy Systems, 28(2006), 548-564.

[13] A.F. Hastings, M. Wattenbach, W. Eugster, C. Li, N Buchmann and P. Smith, Uncertainty propagation in soil greenhouse gas emission models: an experiment using the DNDC model and at the Oensingen cropland site. Agriculture, Ecosystems \& Environment, 136(2010), 97-110.

[14] F. Herrera, E. Herrera-Viedma and F. Chiclana, A study of the origin and uses of the ordered weighted geometric operator in multicriteria decision making, International Journal of Intelligent Systems, 18(2003), 689-707.

[15] IPCC, 2007. Fourth Assessment Report (AR4) of Working Group 1: Chapter 2. Changes in atmospheric constituents and in radiative forcing. http:// www.ipcc.ch/pub/reports.htm.

[16] J. Kacprzyk and S. Zadrożny, Towards a general and unified characterization of individual and collective choice functions under fuzzy and nonfuzzy preferences and majority via the ordered weighted average operators, International Journal of Intelligent Systems, 24(2009), 4-26.

[17] T. Kristensen, L. Mogensen, M.T. Knudsen and J.E. Hermansen, Effect of production system and farming strategy on greenhouse gas emissions from commercial dairy farms in a life cycle approach, Livestock Science, 140(2011), 136-148.

[18] S. Laengle, G. Loyola and J.M. Merigó, Mean-variance portfolio selection with the ordered weighted average, IEEE Transactions on Fuzzy Systems, 25(2017), 350-362.

[19] E. León-Castro, E. Avilés-Ochoa, J.M. Merigó and A.M. GilLafuente, Heavy moving averages and their application in econometric forecasting, Cybernetics and Systems, 49(2018a), 2643.

[20] E. León-Castro, E. Avilés-Ochoa and J.M. Merigó, Induced heavy moving averages, International Journal of Intelligent Systems, 33(2018), 1823-1839.

[21] B. Llamazares, Choosing OWA operator weights in the field of Social Choice, Information Sciences, 177(2007), 4745-4756.

[22] S. Maldonado, J.M., Merigó and J. Miranda, Redefining support vector machines with the ordered weighted average, Knowledge-Based Systems, 148(2018), 41-46.

[23] S. Linares-Mustarós, J.C. Ferrer-Comalat, D. Corominas-Coll and J.M. Merigó, The ordered weighted average in the theory of expertons, International Journal of Intelligent Systems, 34(2019), 345-365.

[24] R. Mesiar, A. Stupňanová and R.R. Yager, Generalizations of OWA operators, IEEE Transactions on Fuzzy Systems, 23(2015), 2154-2162.

[25] J.M. Merigó, A unified model between the weighted average and the induced OWA operator, Expert Systems with Applications, 38(2011), 11560-11572.

[26] J.M. Merigó and M. Casanovas, Fuzzy generalized hybrid aggregation operators and its application in fuzzy decision making, International Journal of Fuzzy Systems, 12(2010a), 15-24. [27] J.M.. Merigo and M. Casanovas, The fuzzy generalized OWA operator and its application in strategic decision making, Cybernetics and Systems, 41(2010b), 359-370.

[28] J.M. Merigó and A.M. Gil-Lafuente, The induced generalized OWA operator, Information Sciences, 179(2009), 729-741.

[29] J.M. Merigo, C. Lobato-Carral A. Carrilero-Castillo, Decision making in the European Union under risk and uncertainty, European Journal of International Management, 6(2012), 590-609.
[30] J.M. Merigó, D. Palacios-Marques and M.M. Mar BenavidesEspinosa, Aggregation methods to calculate the average price, Journal of Business Research, 68(2015), 1574-1580.

[31] J.M. Merigó, D. Palacios-Marqués and P. Soto-Acosta, Distance measures, weighted averages, OWA operators and Bonferroni means, Applied Soft Computing, 50(2017), 356-366.

[32] J.M. Merigó, J.B. Yang and D.L. Xu, Demand analysis with aggregation systems, International Journal of Intelligent Systems, 31(2016a), 425-443.

[33] J.M. Merigó, M. Peris-Ortiz, A. Navarro-Garcia and C. RuedaArmengot, Aggregation operators in economic growth analysis and entrepreneurial group decision-making, Applied Soft Computing, 47(2016b), 141-150.

[34] J.M. Merigó, L. Zhou, D. Yu, N. Alrajeh and K. Alnowibet, Probabilistic OWA distances applied to asset management, Soft Computing, 22(2018), 4855-4878.

[35] W.N. Smith, B.B. Grant, R.L. Desjardins, D. Worth, C. Li, S.H. Boles and E.C. Huffman, A tool to link agricultural activity data with the DNDC model to estimate GHG emission factors in Canada, Agriculture, Ecosystems \& Environment, 136(2010), 301309.

[36] M. Sorrentino, G. Rizzo and L. Sorrentino, A study aimed at assessing the potential impact of vehicle electrification on grid infrastructure and road-traffic green house emissions, Applied Energy, 120(2014), 31-40.

[37] C.E. Stewart, J. Zheng, J. Botte and M.F. Cotrufo, Cogenerated fast pyrolysis biochar mitigates green-house gas emissions and increases carbon sequestration in temperate soils, GCB Bioenergy, 5(2013), 153-164.

[38] V. Torra, The weighted OWA operator, International Journal of Intelligent Systems, 12(1997), 153-166.

[39] V. Torra and Y. Narukawa, Some relationships between Losonczi's based OWA generalizations and the Choquet-Stieltjes integral, Soft Computing, 14(2010), 465-472.

[40] Z. Xu and Q.L. Da, An overview of operators for aggregating information, International Journal of Intelligent Systems, 18(2003), 953-969.

[41] R.R. Yager, On ordered weighted averaging aggregation operators in multi-criteria decision making, IEEE Transactions on Systems, Man, and Cybernetics, 18(1988), 183-190.

[42] R.R. Yager, Families of OWA operators, Fuzzy Sets and Systems, 59(1993), 125-148.

[43] R.R. Yager, Generalized OWA aggregation operators, Fuzzy Optimization and Decision Making, 3(2004), 93-107.

[44] R.R. Yager and D.P. Filev, Induced ordered weighted averaging operators, IEEE Transactions on Systems, Man, and Cybernetics, Part B (Cybernetics), 29(1999), 141-150.

[45] D. Yu, A scientometrics review on aggregation operator research, Scientometrics, 105(2015), 115-133.

[46] D. Yu, D.F. Li, J.M. Merigó and L. Fang, Mapping development of linguistic decision making studies, Journal of Intelligent \& Fuzzy Systems, 30(2016), 2727-2736. 